\title{
NMR Measurement of Identical Polymer Samples by Round Robin Method I. Reliability of Chemical Shift and Signal Intensity Measurements
}

\author{
Riichiro CHÛJÔ, Koichi HATADA, * Ryozo KITAMARU, ${ }^{* *}$ \\ Tatsuki KITAYAMA, ${ }^{*}$ Hisaya SATO, ${ }^{* * *}$ \\ and Yasuyuki TANAKA*** \\ Department of Polymer Chemistry, Tokyo Institute of Technology, \\ Ookayama 2-chome, Meguro-ku, Tokyo 152, Japan \\ * Department of Chemistry, Faculty of Engineering Science, \\ Osaka University, Toyonaka, Osaka 560, Japan \\ **Institute for Chemical Research, Kyoto University, \\ Uji, Kyoto 611, Japan \\ ***Department of Material Systems Engineering, Faculty of Technology, \\ Tokyo University of Agriculture and Technology, \\ Koganei, Tokyo 184, Japan
}

(Received October 31, 1986)

\begin{abstract}
The reliability of NMR data; chemical shift, signal intensity, and resolution, was examined on 26 NMR spectrometers by round robin method using radically prepared poly(methyl methacrylate) and solanesol as identical samples. In the case of poly(methyl methacrylate), the standard deviations $(\sigma)$ of chemical shift measurements for proton and carbon signals were $0.0036-0.0071$ and $0.054-0.307 \mathrm{ppm}$, respectively, with the FT instruments. The $\sigma$ values for the proton signals measured with $\mathrm{CW}$ instruments were slightly larger; $0.0053-0.0169 \mathrm{ppm}$. The relative intensities of $3\left(\mathrm{CH}_{2}+\alpha-\mathrm{CH}_{3}\right) / \mathrm{OCH}_{3}$ were $4.94(\sigma=0.156)$ by FT method and $4.95(\sigma=$ 0.052 ) by $\mathrm{CW}$ method, showing a good agreement with the theoretical value of 5 . The values of triad tacticity obtained from the $\alpha$-proton signals of the PMMA indicate a slight deviation from Bernoullian statistics. The relative peak intensities corrected by the NOE values in the ${ }^{13} \mathrm{C} \mathrm{NMR}$ spectrum of PMMA agreed with the theoretical values within $\pm 10 \%$ relative errors when determined with an appropriate pulse repetition time. In the case of solanesol a $\sigma$ value for the measurement of proton chemical shift was $0.003 \mathrm{ppm}$ with the FT method and 0.039 with the $\mathrm{CW}$ method, while the $\sigma$ for ${ }^{13} \mathrm{C}$ chemical shift was less than $0.05 \mathrm{ppm}$.

KEY WORDS ${ }^{1} \mathrm{H}$ NMR / ${ }^{13} \mathrm{C}$ NMR / Poly(methyl methacrylate) / Solanesol / $\alpha$-Hydro- $\omega$-hydroxy-trans-1,4-nonaisoprene / Round Robin Method / Chemical Shift / Signal Intensity / Precision / Accuracy /
\end{abstract}

NMR spectroscopy has played an important role in many fields of polymer science, including the studies on structure, molecular motion and polymerization mechanism. Introduction of Fourier transform (FT) method and superconducting magnet in NMR technology has opened up new fields of investigation on polymer systems using NMR, besides making it a more powerful tool in routine analysis. However, few were reported on the reliability of NMR data, including chemical shift, signal intensity, nuclear spin relaxation times and nuclear Overhauser effect (NOE) factor. ${ }^{1-8}$ Especially, measurement of signal intensity is very important in polymer science. It can be easily understood after imaging how to determine microtacticities from NMR. It leads to the importance on the reliability of relaxation times and NOE factor, because they have to be determined from intensity. There have also 
been doubts about the consistency between data obtained by different instruments in separate places.

In order to assess the reliability of NMR data, Research Group on NMR, the Society of Polymer Science, Japan (SPSJ), collected ${ }^{1} \mathrm{H}$ and ${ }^{13} \mathrm{C}$ NMR spectra of two identical samples, poly(methyl methacrylate) and solanesol, from a number of NMR spectrometers. Several non-members as well as SPSJ members*1 were invited to participate in this cooperative project. This paper reports on the results of reliability and consistency of chemical shifts and signal intensities obtained from up to 26 NMR spectrometers.

The reports on the measurements of spinlattice relaxation times and NOEs will be published in near future. ${ }^{9}$

\section{EXPERIMENTAL}

\section{Poly(methyl methacrylate)}

Materials. Methyl methacrylate (MMA) was purified by fractional distillation, dried over calcium dihydride and then distilled under high vacuum just before use.

Toluene, purified by usual method and dried over sodium, was mixed with a small amount of butyllithium to remove residual water and then distilled under high vacuum.

$\alpha, \alpha^{\prime}$-Azobisisobutyronitrile (AIBN) was recrystallized from methanol.

Polymerization. Into a dried flask containing $5 \mathrm{mmol}$ of AIBN, 0.5 liter of toluene and $1 \mathrm{~mol}$ of MMA were distilled under high vacuum. After filling the reaction vessel with dry nitrogen, it was immersed in a thermostat at $60^{\circ} \mathrm{C}$ for $24 \mathrm{~h}$. Then, the reaction mixture was pour- ed into 5 liters of methanol to precipitate the polymer formed. The polymer was collected by filtration, washed with methanol, and then dried at $50^{\circ} \mathrm{C}$ for $24 \mathrm{~h}$. Yield was $79 \%$.

Molecular Weight Determination. Gel permeation chromatography (GPC) of the PMMA was performed on a JASCO FLC-A 10 chromatograph equipped with Shodex A-80M GPC column $(50 \mathrm{~cm} \times 2)$ using tetrahydrofuran as an eluent.

The number average molecular weight was also determined using a Hitachi 117 vapor pressure osmometer at $60^{\circ} \mathrm{C}$ in toluene.

$$
\begin{aligned}
& \bar{M}_{n}(\mathrm{GPC})=27400, \quad \bar{M}_{n}(\mathrm{VPO})=28500, \\
& \bar{M}_{w}(\mathrm{GPC})=58000 .
\end{aligned}
$$

\section{Solanesol}

Solanesol was obtained commercially (Kuraray Co., Ltd.; purity $>99 \%$ ) and used without further purification.

\section{Measurement}

PMMA and solanesol samples were packed in glass vials and sent to collaborating test sites with a copy of instructions for NMR measurements, requesting the following measurement conditions;

solvent $\mathrm{CDCl}_{3}$
concentration $10 \mathrm{w} / \mathrm{v} \%$
internal standard $\mathrm{TMS}$
temperature $55^{\circ} \mathrm{C}$ for PMMA
and $50^{\circ} \mathrm{C}$ for solanesol.

${ }^{1} \mathrm{H}$ NMR spectra were measured on $\mathrm{CW}$ and FT NMR spectrometers. ${ }^{13} \mathrm{C}$ NMR spectra were measured on FT NMR instruments. The memory used for acquisition was from 4 to $32 \mathrm{~K}$ for ${ }^{1} \mathrm{H}$ spectra and 8 to $32 \mathrm{~K}$ for ${ }^{13} \mathrm{C}$

*1 S. Amiya (Kuraray Central Research Laboratory), Y. Fujiwara (The University of Tsukuba), Y. Fukasawa (Nippon Zeon Co., Ltd.), Y. Gotoh (University of Tokyo), T. Hayase (Mitsubishi Chemical Industry Co.), T. Hayashi (Denki Kagaku Kogyo Kabushiki Kaisha), K. Hikichi (Hokkaido University), S. Hosoda (Sumitomo Chemical Co., Ltd.), M. Kamachi (Osaka University), K. Kimura (Ube Industries Ltd.), Y. Kobayashi (Osaka University), S. Kohjiya (Kyoto Institute of Technology), A. Matsumoto (Kansai University), T. Sei (Daicel Chemical Industries, Ltd.), T. Seimiya (Idemitsu Kosan Co.), T. Shiibashi (Japan Synthetic Rubber Co.), T. Shimamura (Nitto Technical Information Center Co., Ltd.), Y. Takai (Osaka University), Y. Terawaki (Osaka University), S. Tokuyama (Nippon Oil and Fats Co.), N. Tsuruta (Asahi Chemical Industry Co.), T. Usami (Mitsubishi Petrochemical Co.), K. Ute (Osaka University), B. Yamada (Osaka City University), K. Yokota (Toray Research Center Inc.). 


\section{NMR of Identical Polymer Samples}

Table I. Measurements of ${ }^{1} \mathrm{H}$ NMR spectra of PMMA by twenty-six spectrometers in 1982-1983

\begin{tabular}{|c|c|c|c|c|c|c|c|c|}
\hline & \multirow{2}{*}{$\frac{\text { Freq. }}{\mathrm{MHz}}$} & \multirow{2}{*}{ Instrument $^{a}$} & \multirow{2}{*}{$\frac{\text { Temp }}{{ }^{\circ} \mathrm{C}}$} & \multirow{2}{*}{ Int. ${ }^{b}$} & \multicolumn{2}{|c|}{ Resolution $^{c}$} & \multicolumn{2}{|c|}{ Chemical shift ${ }^{\mathrm{d}}$} \\
\hline & & & & & A & B & A & B \\
\hline G & 90 & FX-90Q & 55 & 4.89 & 0.099 & 0.1724 & $3.66 \quad(0.06)$ & $1.74 \quad(0.05)$ \\
\hline $\mathbf{J}$ & 90 & FX-90Q & 50 & - & 0.082 & 0.1463 & $3.59(-0.01)$ & $1.64(-0.05)$ \\
\hline $\mathrm{L}$ & 90 & FX-90Q & 55 & 4.74 & 0.094 & 0.1741 & $3.59(-0.01)$ & - \\
\hline $\mathrm{O}$ & 90 & FX-90Q & 55 & 5.08 & 0.081 & 0.1394 & $3.60 \quad(0.00)$ & $1.65(-0.04)$ \\
\hline $\mathbf{S}$ & 90 & FX-90Q & 55 & 4.99 & 0.086 & 0.1551 & $3.59(-0.01)$ & $1.73 \quad(0.04)$ \\
\hline-- & $--\cdots$ & $-----\cdots$ & --- & --- & ---1 & ---- & ------ & ------ \\
\hline A & 100 & FX-100 & 55 & 5.03 & 0.070 & 0.0925 & $3.60 \quad(0.00)$ & $1.70 \quad(0.01)$ \\
\hline D & 100 & FX-100 & 55 & 5.14 & 0.067 & 0.0976 & $(0.01)$ & $1.63(-0.06)$ \\
\hline $\mathrm{E}$ & 100 & PS-100 (FT) & 55 & 3.81 & 0.119 & 0.2383 & $3.60 \quad(0.00)$ & $1.75 \quad(0.06)$ \\
\hline $\mathrm{C}$ & 100 & PS- $100^{*}$ & 55 & 4.89 & 0.083 & 0.1283 & $3.59(-0.01)$ & $1.68(-0.01)$ \\
\hline $\mathrm{F}$ & 100 & PS-100* & 55 & 4.60 & 0.070 & 0.1031 & $3.59(-0.01)$ & $1.67(-0.02)$ \\
\hline $\mathrm{P}$ & 100 & PS-100* & 55 & 4.87 & 0.084 & 0.1263 & $3.62 \quad(0.02)$ & $1.72(0.03)$ \\
\hline $\mathbf{R}$ & 100 & PS-100* & 55 & 5.00 & 0.096 & 0.2145 & $(0.00)$ & - \\
\hline B & 100 & MH-100* & 55 & 4.76 & 0.056 & 0.2081 & $3.62 \quad(0.02)$ & $1.78 \quad(0.09)$ \\
\hline $\mathbf{J}$ & 100 & MH-100* & 55 & 5.01 & 0.088 & 0.1373 & $3.57(-0.03)$ & - \\
\hline $\mathrm{Y}$ & 100 & MH-100* & 55 & 4.91 & 0.060 & 0.1082 & $3.59(-0.01)$ & $1.70 \quad(0.01)$ \\
\hline $\mathrm{H}$ & 200 & FX-200 & 55 & 5.06 & 0.043 & 0.0255 & $3.59(-0.01)$ & $1.73 \quad(0.04)$ \\
\hline I & 200 & FX-200 & 55 & 4.95 & 0.047 & 0.0648 & $3.59(-0.01)$ & $1.66(-0.03)$ \\
\hline $\mathrm{Q}$ & 200 & FX-200 & 55 & 4.74 & 0.041 & 0.0535 & $3.60 \quad(0.00)$ & $1.71 \quad(0.02)$ \\
\hline $\mathbf{M}$ & 200 & XL-200 & 55 & 4.41 & 0.052 & 0.0369 & $3.66 \quad(0.00)$ & - \\
\hline-- & --- & ------ & --- & --- & ---1 & ---- & $-\cdots-\cdots$ & ------ \\
\hline W & 270 & GX-270 & 50 & 4.96 & 0.040 & 0.0308 & $3.60 \quad(0.00)$ & $1.58(-0.11)$ \\
\hline $\mathrm{Z}$ & 270 & GX-270 & 55 & 5.15 & 0.038 & 0.0276 & $3.60 \quad(0.00)$ & $1.69 \quad(0.00)$ \\
\hline $\mathrm{X}$ & 360 & AM-360 & 50 & 5.16 & 0.034 & 0.0175 & $3.59(-0.01)$ & $1.75 \quad(0.06)$ \\
\hline & --1 & ----1 & -- & --- & ---1 & ---- & ------- & ------ \\
\hline K & 400 & FX-400 & 45 & 5.09 & 0.035 & 0.0131 & $(0.00)$ & $1.76 \quad(0.07)$ \\
\hline $\mathrm{U}$ & 400 & GX-400 & 55 & 5.23 & 0.040 & 0.0078 & $3.60 \quad(0.00)$ & $1.60(-0.09)$ \\
\hline-- & --- & ----- & ---- & --- & --- & ---- & ------- & ----- \\
\hline $\mathbf{N}$ & 500 & GX-500 & 50 & 4.12 & 0.034 & 0.0170 & $3.60 \quad(0.00)$ & $1.56(-0.13)$ \\
\hline $\mathrm{T}$ & 500 & FX-500S & 55 & 4.90 & 0.030 & 0.0100 & $3.59(-0.01)$ & $1.73 \quad(0.04)$ \\
\hline
\end{tabular}

spectra. The digital resolution of FT NMR spectrum was $0.0003-0.0025 \mathrm{ppm}$ for ${ }^{1} \mathrm{H}$ spectra and $0.006-0.031 \mathrm{ppm}$ for ${ }^{13} \mathrm{C}$ spectra. The pulse width was mostly $45^{\circ}$ and the pulse repetition $4-20 \mathrm{~s}$ for ${ }^{1} \mathrm{H}$ spectra and $1-20 \mathrm{~s}$ for ${ }^{13} \mathrm{C}$ spectra. Peak area was measured by electronic integration or cutting out and weighing method. Accuracy and precision of intensity measurements by these two method were found to be in similar ex- tent. $^{8}$

\section{Instruments}

The number of instruments used was 26 as shown in the third column of Table I. They cover frequency range from 90 to $500 \mathrm{MHz}$. Data were collected from 1982 to 1983 . A part of the results were compared with those obtained in 1969 using 6 continuous wave (CW) spectrometers. 


\section{RESULTS}

\section{${ }^{1} H$ NMR Spectra of PMMA}

${ }^{1} \mathrm{H}$ NMR spectra of the PMMA in $\mathrm{CDCl}_{3}$ were measured on 26 spectrometers, whose resonance frequencies ranged from 90 to $500 \mathrm{MHz}$. Selected spectral data, including chemical shift, relative intensity and resolution, are listed in Table I.

Chemical Shift. Chemical shift data of methoxy $\left(\mathrm{OCH}_{3}\right)$ protons scatter only within $\pm 0.01 \mathrm{ppm}$, with a few exceptions (Table I). The standard deviation is $0.0038 \mathrm{ppm}$ for 19 data obtained from FT instruments and 0.0169 ppm for 7 data obtained from $\mathrm{CW}$ ones (Table II). Standard deviations for $\alpha$-methyl $\left(\alpha-\mathrm{CH}_{3}\right)$ and methylene $\left(\mathrm{CH}_{2}\right)$ proton shifts are less than $0.01 \mathrm{ppm}$. The chemical shift of water which was incidentally introduced into sample solutions are also listed in Table I. The scattering of the values reflects the difference of water contents in the sample solutions which were found to be from 0.07 to $0.20 \%$.

Resolution. In order to express the resolution of spectrum numerically, two kinds of values have been adopted; resolution index $\mathrm{A}$, expressed by half-height width of the signal due to $\alpha$-methyl protons in $r r$ triad, and resolution index $B$, the ratio of the height at the lowest point between $r r$ and $m r$ triad methyl signals, $a$, and the sum of the heights of these two methyl signals, $b+c$ (see Figure 1). Resolution index A represents sharpness of the peak, while resolution index $B$ expresses the degree of peak separation. Both of resolution indices decreased with an increasing magnetic field strength. In particular, the index B decreased, by $1 / 10$ from $90 \mathrm{MHz}$ to $500 \mathrm{MHz}$ (Table I).

Intensity. With only a few exceptions, relative intensity data, $3\left(\mathrm{CH}_{2}+\alpha-\mathrm{CH}_{3}\right) / \mathrm{OCH}_{3}$, agreed with the theoretical value of 5 within $5 \%$ deviation as shown in Table I. Among CW NMR spectrometers, a routine-type instrument, JNM-MH-100, appears to produce accurate results of quantitative determinations
Table II. ${ }^{1} \mathrm{H}$ NMR chemical shifts (ppm) and peak intensity of PMMA

\begin{tabular}{|c|c|c|c|c|c|}
\hline \multirow{2}{*}{\multicolumn{2}{|c|}{ Assignment }} & \multicolumn{2}{|c|}{ FT $(n=19)$} & \multicolumn{2}{|c|}{$\mathrm{CW}(n=7)$} \\
\hline & & $\bar{x}$ & $\sigma^{\mathrm{a}}$ & $\bar{x}$ & $\sigma^{\mathrm{a}}$ \\
\hline \multirow[t]{3}{*}{$\alpha-\mathrm{CH}_{3}$} & $r r$ & 0.869 & 0.0048 & 0.870 & 0.0056 \\
\hline & $m r$ & 1.030 & 0.0036 & 1.033 & 0.0053 \\
\hline & $\mathrm{mm}$ & 1.214 & 0.0071 & 1.211 & 0.0077 \\
\hline \multirow{2}{*}{$\mathrm{CH}_{2}$} & $r r r$ & 1.823 & 0.0051 & 1.824 & 0.0085 \\
\hline & $\mathrm{rrm}$ & 1.897 & 0.0059 & 1.899 & 0.0081 \\
\hline \multicolumn{2}{|c|}{$\mathrm{OCH}_{3}$} & 3.596 & 0.0038 & 3.600 & 0.0169 \\
\hline \multicolumn{2}{|c|}{$\mathrm{CHCl}_{3}$} & 7.287 & 0.0143 & 7.298 & 0.0268 \\
\hline \multicolumn{2}{|c|}{$\begin{array}{c}3\left(\mathrm{CH}_{2}+\alpha-\mathrm{CH}_{3}\right) / \\
\mathrm{OCH}_{3}{ }^{b}\end{array}$} & $4.938^{c}$ & $0.1561^{\mathrm{c}}$ & 4.947 & 0.0523 \\
\hline
\end{tabular}

a $\rho=\sqrt{\sum\left(x_{i}-\bar{x}\right)^{2} / n}$

b Relative intensity.

c $n=18$.

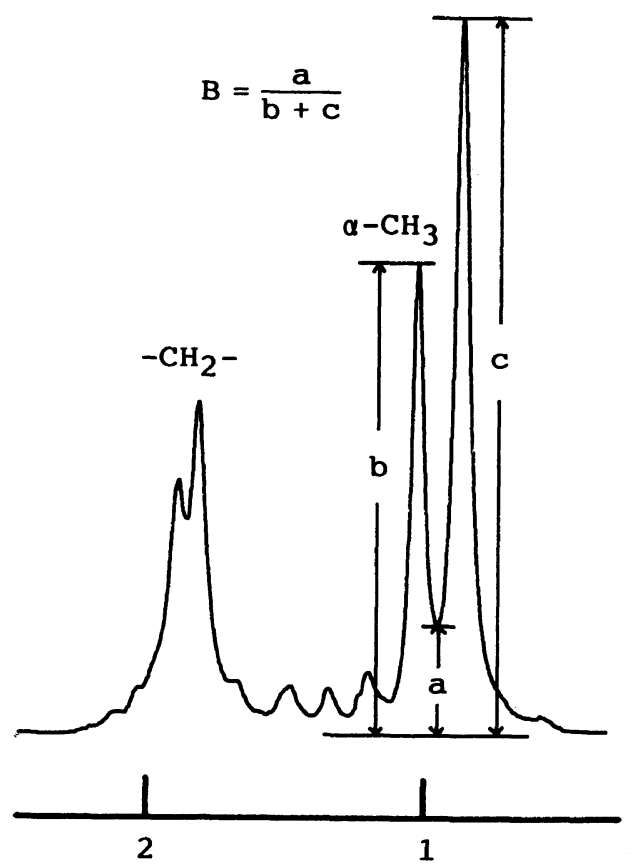

Figure 1. NMR spectrum of $\alpha-\mathrm{CH}_{3}$ protons in PMMA measured in $\mathrm{CDCl}_{3}$ at $55^{\circ} \mathrm{C}$ and $100 \mathrm{MHz}$.

comparable with those obtained from more elaborate ones.

Comparison with an Assessment in 1969. In 1969, a similar assessment was done by Hatada et al. $^{2} \mathrm{~A} \mathrm{CDCl}_{3}$ solution of PMMA synthesized by radical polymerization under similar 
NMR of Identical Polymer Samples

Table III. Measurements of ${ }^{1} \mathrm{H}$ NMR spectra of PMMA on six spectrometers in 1969

\begin{tabular}{|c|c|c|c|c|c|c|c|c|}
\hline & \multirow{2}{*}{$\frac{\text { Freq. }}{\mathrm{MHz}}$} & \multirow{2}{*}{ Instrument } & \multirow{2}{*}{$\frac{\text { Temp }}{{ }^{\circ} \mathrm{C}}$} & \multirow{2}{*}{ Int. $^{\mathrm{a}}$} & \multicolumn{2}{|c|}{ Resolution $^{\mathbf{b}}$} & \multicolumn{2}{|c|}{ Chemical shift ${ }^{c}$} \\
\hline & & & & & A & B & A & B \\
\hline A & 60 & A- $60 \mathrm{~A}$ & 65 & 4.95 & 0.078 & 0.1587 & $3.59(-0.02)$ & $1.54(-0.07)$ \\
\hline B & 60 & C-60HL & 65 & 4.99 & 0.115 & 0.2530 & $3.65 \quad(0.04)$ & $1.66 \quad(0.06)$ \\
\hline- & --- & ------ & ---1 & --- & --- & ---- & $-----\cdots$ & ------ \\
\hline $\mathrm{C}$ & 100 & $4 \mathrm{H}-100$ & 59 & 5.03 & 0.068 & 0.1202 & $3.61 \quad(0.00)$ & $1.58(-0.03)$ \\
\hline D & 100 & $4 \mathrm{H}-100$ & 60 & 5.34 & 0.064 & 0.1028 & $3.58(-0.03)$ & $1.59(-0.02)$ \\
\hline $\mathrm{E}$ & 100 & $4 \mathrm{H}-100$ & 50 & 5.07 & 0.080 & 0.1446 & $3.63 \quad(0.02)$ & $1.68 \quad(0.08)$ \\
\hline $\mathrm{F}$ & 100 & HA-100 & 59 & 5.22 & 0.080 & 0.1771 & $3.59(-0.02)$ & $1.58(-0.03)$ \\
\hline
\end{tabular}

a Relative intensity of $3\left(\mathrm{CH}_{2}+\alpha-\mathrm{CH}_{3}\right) / \mathrm{OCH}_{3}$.

b A, half-height width (ppm) of $\alpha-\mathrm{CH}_{3}(r r)$ signal; B, $a /(b+c)$ see Figure 1 .

c Chemical shifts (ppm) of $\mathrm{OCH}_{3}(\mathrm{~A})$ and $\mathrm{H}_{2} \mathrm{O}(\mathrm{B})$ signals. The values in parentheses represent $\left(x_{i}-\bar{x}\right)$.

conditions to those for the PMMA sample used in the present assessment was subjected to the measurements on six $\mathrm{CW}$ instruments. Table III lists the old data to allow comparison with those collected at this time. Mean values and standard deviations, are summarized in Table IV. Comparison of the results obtained at $100 \mathrm{MHz}$ in Tables III and IV with those in Tables I and II indicates that there is no substantial difference in the accuracy of relative intensity and resolution between these two sets of data. Mean values of chemical shift obtained in 1969 and at present are in agreement within $0.01 \mathrm{ppm}$ for each peak. Standard deviations for chemical shift are slightly smaller in the present measurements than in 1969, while the deviation for relative intensity is smaller in the measurement in 1969. It is noteworthy that in both cases standard deviation for the chemical shifts of $\mathrm{OCH}_{3}$ and $\mathrm{CHCl}_{3}$ signals are larger than those for the shifts of other signals. A large standard deviation for $\mathrm{H}_{2} \mathrm{O}$ signal obtained in 1969 may have reflected the difference in the temperature of measurement because the sample solution was the same for all the measurements.

\section{${ }^{13}$ C NMR Spectra of PMMA}

The ${ }^{13} \mathrm{C}$ NMR spectra were measured on 24 instruments, whose resonance frequencies ranged from 15.0 to $125 \mathrm{MHz}$. The data are
Table IV. ${ }^{1} \mathrm{H}$ NMR chemical shifts (ppm) and peak intensity of PMMA measured by six spectrometers in 1969

\begin{tabular}{llcc}
\hline \multicolumn{1}{c}{ Assignment } & $\bar{x}$ & $\sigma^{\mathrm{a}}$ \\
\hline$\alpha-\mathrm{CH}_{3}$ & $r r$ & 0.880 & 0.0098 \\
& $m r$ & 1.041 & 0.0126 \\
& $m m$ & 1.226 & 0.0193 \\
$\mathrm{CH}_{2}{ }^{\mathrm{b}}$ & $r r r$ & 1.827 & 0.0100 \\
& $r r m$ & 1.905 & 0.0133 \\
$\mathrm{OCH}_{3}$ & 3.608 & 0.0223 \\
$\mathrm{CHCl}_{3}{ }^{\mathrm{b}}$ & 7.265 & 0.0190 \\
$\mathrm{H}_{2} \mathrm{O}$ & 1.605 & 0.0489 \\
$3\left(\mathrm{CH}_{2}+\alpha-\mathrm{CH}_{3}\right) / \mathrm{OCH}_{3}{ }^{\mathrm{c}}$ & 5.100 & 0.1368 \\
\hline
\end{tabular}

a $\rho=\sqrt{\sum\left(x_{i}-\bar{x}\right)^{2} / n}$.

b Number of determinations: 5 for $\mathrm{CH}_{2}, 4$ for $\mathrm{CHCl}_{3}$.

c Relative intensity.

summarized in Tables V and VI.

Chemical Shift. All carbons except for methoxy one were sensitive to the tacticity of the polymer chain. The number of distinguishable peaks depends on magnetic field strength. In Table VI, mean values and standard deviations for chemical shift are listed with number of determinations, $n$. The deviations vary from 0.1 to $0.3 \mathrm{ppm}$, excluding those for methoxy and $\mathrm{CDCl}_{3}$ carbons. Precisions of chemical shift for methoxy and $\mathrm{CDCl}_{3}$ carbons were better than those for others, in contrast to the case of ${ }^{1} \mathrm{H}$ NMR. As compared with the case of solanesol, PMMA shows lower precision of 
R. CHÛ̉ô et al.

Table V. Measurements of ${ }^{13} \mathrm{C}$ NMR spectra of PMMA by twenty-three spectrometers in 1982-1983

\begin{tabular}{|c|c|c|c|c|c|c|c|c|c|}
\hline & \multirow{2}{*}{$\frac{\text { Freq. }}{\mathrm{MHz}}$} & \multirow{2}{*}{ Instrument } & \multirow{2}{*}{$\frac{\text { Temp }}{{ }^{\circ} \mathrm{C}}$} & \multicolumn{3}{|c|}{ Int. $^{a}$} & \multicolumn{2}{|c|}{ Resolution $^{\mathrm{b}}$} & \multirow{2}{*}{$\begin{array}{l}\text { Chemical } \\
\text { shift }^{c}\end{array}$} \\
\hline & & & & A & B & $\mathrm{C}$ & A & B & \\
\hline B & 15.0 & FX-60 & 55 & $(2.30)$ & $(3.00)$ & $(2.90)$ & - & 0.1448 & $17.17 \quad(0.27)$ \\
\hline $\mathbf{R}$ & 15.0 & FX-60Q & 25 & $(4.02)$ & (3.49) & $(4.29)$ & - & 0.1078 & $16.57(-0.33)$ \\
\hline \multicolumn{10}{|c|}{ 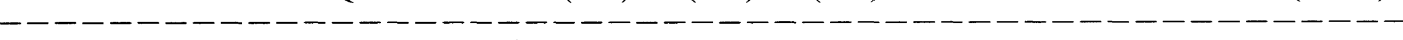 } \\
\hline G & 22.5 & FX-90Q & 25 & 0.91 & 1.95 & 1.03 & 一 & 0.1754 & $16.90 \quad(0.00)$ \\
\hline $\mathbf{J}$ & 22.5 & FX-90Q & 50 & $(3.14)$ & $(4.12)$ & (3.54) & - & 0.0277 & $(0.02)$ \\
\hline L & 22.5 & FX-90Q & 55 & 1.05 & 2.11 & 1.10 & 0.115 & 0.0530 & $(0.02)$ \\
\hline $\mathrm{O}$ & 22.5 & FX-90Q & 55 & 0.85 & 1.98 & 0.99 & 0.158 & 0.1477 & $(0.28)$ \\
\hline V & 22.5 & FX-90Q & 55 & 0.84 & 2.01 & 1.07 & 0.100 & 0.0411 & $16.94 \quad(0.04)$ \\
\hline $\mathbf{P}$ & 22.5 & $\mathrm{R} 90-\mathrm{H}$ & 23 & 0.81 & 1.86 & 0.99 & 0.084 & 0.0366 & $16.61(-0.29)$ \\
\hline A & 25.0 & FX-100 & 55 & 0.98 & 2.12 & 1.03 & 0.078 & 0.0308 & $17.01 \quad(0.11)$ \\
\hline $\mathrm{C}$ & 25.0 & FX-100 & 55 & 1.0 & 2.0 & 1.1 & - & 0.1172 & $16.81(-0.09)$ \\
\hline $\mathrm{D}$ & 25.0 & FX-100 & 55 & 1.22 & 2.11 & 1.11 & 0.131 & 0.0810 & $17.08 \quad(0.18)$ \\
\hline $\mathrm{F}$ & 25.0 & FX-100 & 55 & 0.83 & 1.91 & 0.95 & - & 0.0975 & $(0.06)$ \\
\hline $\mathrm{S}$ & 25.0 & FX-100 & 55 & 0.76 & 1.98 & 1.03 & - & 0.0752 & $16.94 \quad(0.04)$ \\
\hline $\mathrm{E}$ & 25.0 & PS-100 & 55 & $(3.45)$ & $(3.52)$ & $(2.83)$ & - & 0.1301 & $16.82(-0.08)$ \\
\hline $\mathrm{H}$ & 50.1 & FX-200 & 55 & 0.59 & 1.69 & 0.88 & 0.080 & 0.0126 & $16.91 \quad(0.01)$ \\
\hline I & 50.1 & FX-200 & 55 & 0.35 & 1.94 & 0.93 & 0.093 & 0.0393 & $(0.20)$ \\
\hline Q & 50.1 & FX-200 & 55 & 0.67 & 1.74 & 0.94 & 0.110 & 0.0589 & $(0.03)$ \\
\hline M & 50.3 & XL-200 & 55 & 1.15 & 2.22 & 1.60 & - & 0.0939 & $16.93 \quad(0.03)$ \\
\hline & ---1 & ----- & -- & --- & ---- & --- & --- & --- & ------1 \\
\hline W & 67.8 & GX-270 & 50 & 0.40 & 1.38 & 0.65 & 0.081 & 0.0417 & $16.83(-0.07)$ \\
\hline $\mathrm{Z}$ & 67.8 & GX-270 & 55 & 0.55 & 1.52 & 0.75 & 0.074 & 0.0605 & $16.94 \quad(0.04)$ \\
\hline$x$ & 90 & AM-360 & 50 & 0.43 & 1.33 & 0.70 & 0.100 & 0.0073 & $16.85(-0.05)$ \\
\hline- & --- & ---- & --- & ---1 & ---1 & --- & --- & ---- & ------- \\
\hline $\mathrm{K}$ & 100 & FX-400 & 25 & 1.10 & 2.24 & 1.18 & 0.090 & 0.0494 & $16.46(-0.44)$ \\
\hline $\mathrm{U}$ & 100 & FX-400 & 55 & 0.33 & 1.54 & 0.67 & 0.059 & 0.0333 & $16.96 \quad(0.06)$ \\
\hline $\mathrm{N}$ & 125 & GX-500 & 50 & $(1.85)$ & $(2.89)$ & $(2.22)$ & 0.061 & 0.0424 & $16.84(-0.06)$ \\
\hline
\end{tabular}

a Relative intensities of $\mathrm{CO} / \alpha-\mathrm{CH}_{3}$ (A), $\left(\mathrm{OCH}_{3}+\mathrm{CH}_{2}\right) / \alpha-\mathrm{CH}_{3}$ (B) and Quat. $\mathrm{C} / \alpha-\mathrm{CH}_{3}$ (C). The values in parentheses were determined from peak heights.

b A, half-height width (ppm) of CO $(r r r r)$ signal; B, $a /(b+c)$ see Figure 2.

c Chemical shifts (ppm) of $\alpha-\mathrm{CH}_{3}(r r)$ signal. The values in parentheses represent $\left(x_{i}-\bar{x}\right)$.

chemical shift ( $c f$. Tables IV and XI).

Resolution. Resolution of ${ }^{13} \mathrm{C}$ NMR spectrum is expressed numerically by two indices as in the case of ${ }^{1} \mathrm{H}$ NMR; resolution index $\mathrm{A}$, half-height width of carbonyl carbon signal in rrrr pentad, resolution index $\mathrm{B}$, ratio of height at the lowest point between rrrr and rrrm pentad signals of carbonyl carbon and the sum of peak heights of them (see Figure 2). Both of resolution indices decreased with an increase of the magnetic field, although the improve- ment in resolution was not as remarkable as in the case of ${ }^{1} \mathrm{H}$ NMR. Resolution indices in the case of ${ }^{13} \mathrm{C}$ NMR seem to scatter more widely, depending on individual instruments, than those in the case of ${ }^{1} \mathrm{H}$ NMR.

Intensity. Relative peak intensities for carbonyl, (methoxy + methylene) and quaternary carbons against $\alpha$-methyl carbon are listed in Table V. Accuracy of these values were much poorer than those of ${ }^{1} \mathrm{H}$ NMR. Only four instruments were found to give data agreeable 
Table VI. ${ }^{13} \mathrm{C}$ NMR chemical shifts (ppm) of PMMA measured by a number of spectrometers in $1982-1983$

\begin{tabular}{|c|c|c|c|c|}
\hline \multicolumn{2}{|c|}{ Assignment } & $\bar{x}$ & $\sigma^{\mathrm{a}}$ & $n$ \\
\hline \multirow[t]{3}{*}{$\alpha-\mathrm{CH}_{3}$} & $r r$ & 16.899 & 0.1661 & 24 \\
\hline & $m r$ & 19.025 & 0.1120 & 24 \\
\hline & $m m$ & 21.322 & 0.1579 & 17 \\
\hline \multirow[t]{3}{*}{ Quat. } & $r r$ & 44.808 & 0.1257 & 24 \\
\hline & $m r$ & 45.120 & 0.1211 & 24 \\
\hline & $\mathrm{mm}$ & 45.725 & 0.1047 & 20 \\
\hline \multicolumn{2}{|c|}{$\mathrm{OCH}_{3}$} & 51.667 & 0.0544 & 24 \\
\hline \multirow[t]{6}{*}{$\mathrm{CH}_{2}$} & $m r r$ & 52.755 & 0.1720 & 23 \\
\hline & $m m r$ & 53.574 & 0.2140 & 20 \\
\hline & $r r r r r$ & 54.249 & 0.3067 & 23 \\
\hline & rrrrm & 54.571 & 0.0984 & 22 \\
\hline & $r r m r r$ & 54.636 & 0.0892 & 7 \\
\hline & rrmrm & 54.710 & 0.0600 & 2 \\
\hline \multicolumn{2}{|c|}{$\mathrm{CDCl}_{3}$} & 77.070 & 0.0587 & 24 \\
\hline \multirow[t]{7}{*}{$\mathrm{CO}$} & $r \dot{m m r}$ & 176.053 & 0.1967 & 15 \\
\hline & $m m m r$ & 176.250 & 0.0777 & 6 \\
\hline & $\left.\begin{array}{l}m m r r \\
r m r r\end{array}\right\}$ & 176.831 & 0.1227 & 23 \\
\hline & $\mathrm{rmrm}$ & 177.018 & 0.1234 & 23 \\
\hline & $r r r r$ & 177.646 & 0.1349 & 24 \\
\hline & rrrm & 177.918 & 0.1200 & 24 \\
\hline & mrrm & 178.205 & 0.1409 & 17 \\
\hline \multirow{3}{*}{\multicolumn{2}{|c|}{$\begin{array}{l}\mathrm{CO} / \alpha-\mathrm{CH}_{3} \\
\left(\mathrm{OCH}_{3}+\mathrm{CH}_{2}\right) / \alpha-\mathrm{CH}_{3} \\
\text { Quat. } \mathrm{C} / \alpha-\mathrm{CH}_{3}\end{array}$}} & 1.183 & 0.2716 & 19 \\
\hline & & 2.115 & 0.3927 & 19 \\
\hline & & 1.379 & 0.2179 & 19 \\
\hline
\end{tabular}

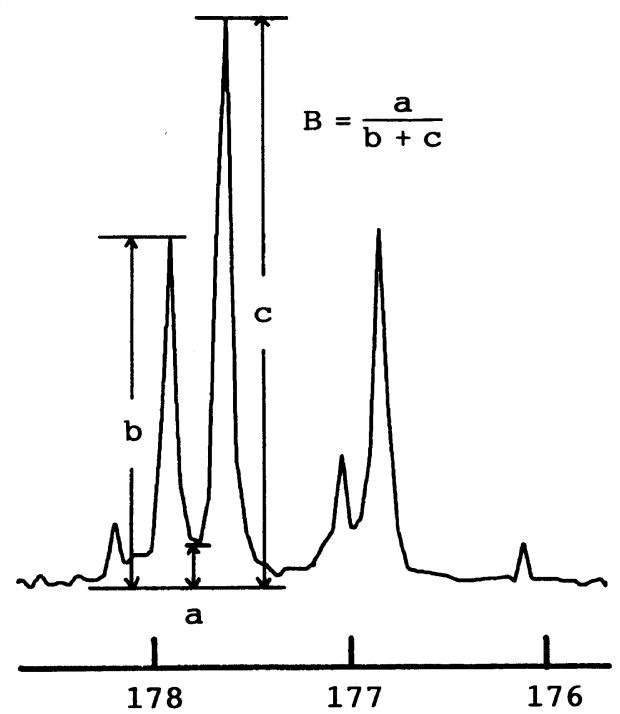

Figure 2. NMR spectrum of $\mathrm{CO}$ carbon in PMMA measured in $\mathrm{CDCl}_{3}$ at $55^{\circ} \mathrm{C}$ and $25.0 \mathrm{MHz}$.
Table VII. Intensities of ${ }^{13} \mathrm{C}$ NMR signals of PMMA in $\mathrm{CDCl}_{3}$ at $55^{\circ} \mathrm{C}$

\begin{tabular}{|c|c|c|c|c|c|c|c|}
\hline \multirow{3}{*}{$\frac{\text { Freq. }}{\mathrm{MHz}}$} & \multirow{3}{*}{$n^{\mathrm{a}}$} & \multicolumn{6}{|c|}{ Signal intensity ${ }^{\mathbf{b}}$} \\
\hline & & \multicolumn{3}{|c|}{ Observed } & \multicolumn{3}{|c|}{ Corrected by NOE } \\
\hline & & A & B & $\mathrm{C}$ & A & B & $\mathrm{C}$ \\
\hline 22.5 & 3 & 0.86 & 1.93 & 1.00 & 1.11 & 2.15 & 1.07 \\
\hline 25 & 3 & 0.86 & 2.00 & 1.00 & 1.04 & 2.07 & 1.08 \\
\hline 50 & 3 & 0.54 & 1.45 & 0.92 & 0.87 & 1.80 & 1.14 \\
\hline 67.5 & 1 & 0.55 & 1.52 & 0.75 & 1.01 & 1.94 & 0.96 \\
\hline 90.6 & 1 & 0.43 & 1.33 & 0.70 & 0.62 & 1.61 & 0.72 \\
\hline 100 & 1 & 0.33 & 1.54 & 0.67 & 0.66 & 2.05 & 0.84 \\
\hline
\end{tabular}

a Number of determinations.

b $\mathrm{A}, \mathrm{B}$, and $\mathrm{C}$ denote the relative intensities of $\mathrm{C}=\mathrm{O} / \alpha$ $\mathrm{CH}_{3},\left(\mathrm{OCH}_{3}+\mathrm{CH}_{2}\right) / \alpha-\mathrm{CH}_{3}$ and Quat. $\mathrm{C} / \alpha-\mathrm{CH}_{3}$.

Table VIII. Tacticity ( $\%$ ) of PMMA determined by ${ }^{1} \mathrm{H}$ NMR spectroscopy

\begin{tabular}{|c|c|c|c|c|}
\hline & Instrument & $I$ & $H$ & $S$ \\
\hline $\mathrm{O}$ & FX-90Q & 3.3 & 35.3 & 61.4 \\
\hline \multicolumn{5}{|c|}{------------------------} \\
\hline A & FX-100 & 2.8 & 34.0 & 63.2 \\
\hline D & FX-100 & 3.9 & 34.9 & 61.2 \\
\hline $\mathrm{F}$ & PS-100* & 4.1 & 34.2 & 61.8 \\
\hline $\mathbf{P}$ & PS-100* & 4.4 & 36.4 & 59.1 \\
\hline $\mathrm{R}$ & PS-100* & 5.7 & 37.3 & 57.0 \\
\hline$Y$ & MH-100* & 3.3 & 34.2 & 62.5 \\
\hline $\mathbf{H}$ & FX-200 & 3.7 & 35.6 & 60.7 \\
\hline Q & FX-200 & 5.4 & 33.7 & 60.9 \\
\hline $\mathbf{M}$ & XL-200 & 5.0 & 35.0 & 60.0 \\
\hline \multicolumn{5}{|c|}{$--------------------\cdots$} \\
\hline W & GX-270 & 3.8 & 34.5 & 61.7 \\
\hline $\mathrm{Z}$ & GX-270 & 4.8 & 33.8 & 61.4 \\
\hline $\mathbf{X}$ & AM-360 & 4.3 & 33.6 & 62.2 \\
\hline \multicolumn{5}{|c|}{$----------------\cdots---1$} \\
\hline $\mathbf{K}$ & FX-400 & 3.9 & 34.7 & 61.4 \\
\hline $\mathrm{U}$ & GX-400 & 3.4 & 34.9 & 61.7 \\
\hline 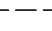 & ----1 & -- & --- & --- \\
\hline $\mathbf{N}$ & GX-500 & 2.4 & 35.3 & 62.3 \\
\hline \multirow[t]{3}{*}{$\mathrm{T}$} & GX-500S & 3.5 & 33.1 & 63.4 \\
\hline & $\bar{x}$ & 4.0 & 34.7 & 61.3 \\
\hline & $\sigma$ & 0.9 & 1.0 & 1.5 \\
\hline
\end{tabular}

with theoretical values in all three relative intensities within $\pm 10 \%$ deviation $(\mathrm{A}, \mathrm{C}, \mathrm{G}, \mathrm{L}$ in Table $\mathrm{V})$. The deviations were $\pm 20 \%$ on 
Table IX. Tacticity (\%) of PMMA determined by ${ }^{13} \mathrm{C}$ NMR spectroscopy

\begin{tabular}{|c|c|c|c|c|c|c|c|}
\hline & \multirow{2}{*}{ Instrument } & \multicolumn{3}{|c|}{$\alpha-\mathrm{CH}_{3}$} & \multicolumn{3}{|c|}{ Quat. C } \\
\hline & & $I$ & $H$ & $S$ & $I$ & $H$ & $S$ \\
\hline G & FX-90Q & 2.7 & 38.1 & 59.3 & 4.6 & 34.0 & 61.3 \\
\hline $\mathrm{O}$ & FX-90Q & - & - & - & 3.0 & 33.3 & 63.7 \\
\hline $\mathrm{V}$ & FX-90Q & 4.4 & 33.0 & 62.6 & 6.3 & 31.2 & 62.5 \\
\hline $\mathbf{P}$ & R90-H & 3.5 & 36.5 & 60.0 & 3.9 & 37.0 & 59.0 \\
\hline \multicolumn{8}{|l|}{---} \\
\hline A & FX-100 & 2.7 & 36.8 & 60.5 & 3.1 & 33.4 & 65.3 \\
\hline $\mathrm{C}$ & FX-100 & 6.1 & 33.9 & 60.0 & - & - & - \\
\hline D & FX-100 & 2.0 & 32.7 & 65.3 & 5.2 & 29.8 & 65.0 \\
\hline $\mathrm{F}$ & FX-100 & 1.8 & 33.6 & 64.6 & 3.0 & 34.6 & 62.4 \\
\hline $\mathbf{S}$ & FX-100 & 3.2 & 35.4 & 61.3 & 3.3 & 35.4 & 61.4 \\
\hline \multicolumn{8}{|c|}{ 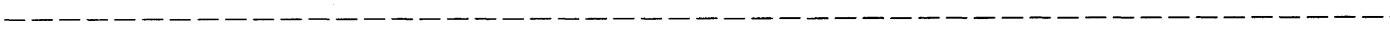 } \\
\hline $\mathbf{H}$ & FX-200 & 3.2 & 34.9 & 61.9 & 3.4 & 35.2 & 61.5 \\
\hline I & FX-200 & 2.5 & 36.6 & 60.8 & 4.2 & 35.4 & 60.4 \\
\hline Q & FX-200 & 2.2 & 34.9 & 62.9 & 2.4 & 31.3 & 66.4 \\
\hline \multicolumn{8}{|c|}{ 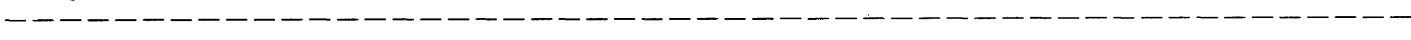 } \\
\hline W & GX-270 & 2.3 & 32.4 & 65.3 & 2.4 & 37.9 & 59.7 \\
\hline $\mathrm{Z}$ & GX-270 & 5.1 & 36.1 & 58.8 & 5.7 & 42.1 & 52.2 \\
\hline \multicolumn{8}{|c|}{$--------------------------------------\cdots------$} \\
\hline X & AM-360 & 1.8 & 34.2 & 63.9 & 1.9 & 35.9 & 62.2 \\
\hline K & FX-400 & 1.1 & 35.2 & 63.7 & - & - & - \\
\hline $\mathrm{U}$ & GX-400 & 3.7 & 34.7 & 61.5 & 4.3 & 38.7 & 57.0 \\
\hline \multirow{3}{*}{$\mathrm{N}$} & GX-500 & 31 & 330 & 639 & - & - & - \\
\hline & $\bar{x}$ & 3.0 & 34.8 & 62.2 & 3.8 & 35.0 & 61.3 \\
\hline & $\sigma$ & 1.3 & 1.6 & 2.0 & 1.3 & 3.1 & 3.4 \\
\hline
\end{tabular}

average for the data obtained from 22.5 or $25 \mathrm{MHz}$ instruments. On the other hand, relative intensities obtained by $15 \mathrm{MHz}$ and $50 \mathrm{MHz}$ or higher frequency instruments generally show large negative deviations. One of the sources of errors in these quantitative measurements is the variation in NOE values. The NOE values for each carbon measured at 22.5 and $25 \mathrm{MHz}$ were close to 2.99 and the differences between the types of carbon were not large enough to perturb the intensity measurements significantly. However, the NOE decreased with an increasing magnetic field strength strongly depending on the type of carbon. ${ }^{9}$ The relative peak intensities listed in Table $\mathrm{V}$ were corrected by the NOE values and the results are shown in Table VII. Agreement within $\pm 10 \%$
Table X. Mean values of tacticity for PMMA measured at different field strength

\begin{tabular}{|c|c|c|c|c|c|}
\hline \multirow{2}{*}{ Frequency/MHz } & \multirow{2}{*}{$n$} & \multicolumn{3}{|c|}{ Tacticity $/ \%$} & \multirow{2}{*}{$\frac{4 I S}{H^{2}}$} \\
\hline & & $I$ & $H$ & $S$ & \\
\hline 100 & 6 & 4.0 & 35.2 & 60.8 & 0.79 \\
\hline 200 & 3 & 4.7 & 34.8 & 60.5 & 0.94 \\
\hline 270 & 2 & 4.3 & 34.2 & 61.5 & 0.90 \\
\hline 360 & 1 & 4.3 & 33.6 & 62.2 & 0.95 \\
\hline 400 & 2 & 3.7 & 34.8 & 61.5 & 0.75 \\
\hline $400^{\mathrm{a}}$ & (5) & 3.5 & 33.6 & 62.9 & 0.78 \\
\hline 500 & 2 & 3.0 & 34.2 & 62.8 & 0.64 \\
\hline $500^{a}$ & (5) & 3.2 & 34.0 & 62.8 & 0.70 \\
\hline
\end{tabular}

a Results from five runs on the same spectrometer.

relative errors were obtained in the measurements at the field strength of $22.5-67.5 \mathrm{MHz}$. The corrected values for 90.6 and $100 \mathrm{MHz}$ 
still showed the negative deviations. This may be due to saturation of the resonances since the pulse repetition of about $1 \mathrm{~s}$ were used in the measurements at 90.6 and $100 \mathrm{MHz}$ in this work while the spin-lattice relaxation times increase by a factor of at most 2.5 when the magnetic field is changed from 25 to $100 \mathrm{MHz}^{9}$

\section{Tacticity of PMMA Determined by ${ }^{1} \mathrm{H}$ and ${ }^{13} \mathrm{C}$ NMR}

Tacticity is one of the most valuable data obtainable from NMR spectra and stereochemical assignments of ${ }^{1} \mathrm{H}$ and ${ }^{13} \mathrm{C}$ NMR spectra of PMMA are well established. Triad tacticities were determined from intensity ratios of split signals of $\alpha-\mathrm{CH}_{3}$ protons, and those of $\alpha-\mathrm{CH}_{3}$ and quaternary carbons (Tables VIII and IX). Mean values derived from these signals were in good agreement with each other, although the values from quaternary carbon signals show larger standard deviations than others. This may be the results of the smaller shifts between the peaks and of the narrower peak widths; the latter cause a smaller number of data point defining the line shape. In the assessment in $1969,^{2}$ mean values, $x$, for each triad tacticities and their standard deviations, $\sigma$, were found to be as follows;

$$
\begin{array}{lll}
m m, & x=6.0 \%, & \sigma=1.0 \\
m r, & x=34.6 \%, & \sigma=1.4 \\
r r, & x=59.4 \%, & \sigma=2.3 .
\end{array}
$$

The values agree with those obtained in the present assessment.

Configurational sequences of PMMA prepared by radical initiator was first reported to be described by Bernoullian statistics within experimental limits of resolution in the measurement at $60 \mathrm{MHz}{ }^{10}$ Later, several reinvestigations at higher magnetic field strength indicated that first-order Markovian statistics rather than Bernoullian statistics could apply to radically prepared PMMA. ${ }^{1,11,12}$ Mean values of tacticity measured by ${ }^{1} \mathrm{H}$ NMR at different frequencies were calculated from data in Table VIII and listed in Table X. The values of $4 I S / H^{2}$, which is equal to unity when tacticity is completely described by Bernoullian statistics, ${ }^{13}$ are less than unity in all the measurements. The signal to noise ratio and the degree of peak separation were greatly enhanced at higher field strength. In order to

\begin{tabular}{|c|c|c|c|c|c|c|c|c|c|c|}
\hline \multirow{2}{*}{\multicolumn{2}{|c|}{ Proton $^{\mathrm{a}}$}} & \multicolumn{4}{|c|}{ Chemical shift ${ }^{b}$} & \multicolumn{5}{|c|}{ Relative intensity ${ }^{b}$} \\
\hline & & FT & $(n=16)$ & $\mathrm{CW}$ & $(n=4)$ & FT & $(n=16)$ & $\mathrm{CW}$ & $(n=4)$ & Theory \\
\hline trc & $\mathrm{CH}_{3}$ & 1.598 & $(0.003)$ & 1.581 & $(0.024)$ & .23 .92 & $(0.80)$ & 23.93 & $(1.03)$ & 24 \\
\hline & $\mathrm{CH}_{3}$ & 1.675 & $(0.002)$ & 1.662 & $(0.029)$ & 6.00 & $(0.50)$ & 6.43 & $(0.59)$ & 6 \\
\hline $\mathrm{m}$ & $\mathrm{CH}_{2}$ & 2.004 & $(0.017)$ & 1.094 & $(0.032)$ & 32.55 & $(0.72)$ & 32.03 & $(0.87)$ & 32 \\
\hline$\omega$ & $\mathrm{CH}_{2} \mathrm{OH}$ & 4.136 & $(0.004)$ & 4.111 & $(0.046)$ & 1.81 & $(0.22)$ & 1.80 & $(0.21)$ & 2 \\
\hline $\mathrm{m}$ & $=\mathrm{CH}-$ & 5.109 & $(0.016)$ & 5.153 & $(0.051)$ & 7.76 & $(0.55)$ & 8.00 & $(0.08)$ & 8 \\
\hline \multirow[t]{2}{*}{$\omega$} & $=\mathrm{CH}-$ & 5.415 & $(0.003)$ & 5.447 & $(0.072)$ & 0.98 & $(0.12)$ & 0.93 & $(0.05)$ & 1 \\
\hline & $\mathrm{CHCl}_{3}$ & 7.246 & $(0.005)$ & 7.231 & $(0.023)$ & & - & & - & - \\
\hline \multicolumn{3}{|c|}{ Average } & \multicolumn{2}{|l|}{$(0.003)^{c}$} & $(0.039)^{\mathrm{c}}$ & \multicolumn{2}{|r|}{$(0.44)^{c}$} & \multicolumn{3}{|c|}{$(0.47)^{\mathrm{c}}$} \\
\hline
\end{tabular}
make sure the deviation from unity, the

Table XI. $\quad{ }^{1} \mathrm{H}$ NMR chemical shifts (ppm) and relative intensities of solanesol

\footnotetext{
a Notation:

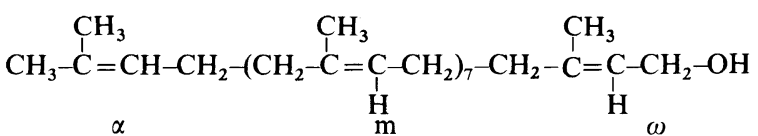

b The values in parentheses represent standard deviation, $\sqrt{\sum\left(x_{i}-\bar{x}\right)^{2} / n}$.

c The data on the signals due to $\mathrm{CH}_{2}(2.0 \mathrm{ppm})$ and $=\mathrm{CH}(5.1 \mathrm{ppm})$ are omitted on the calculation.
} 


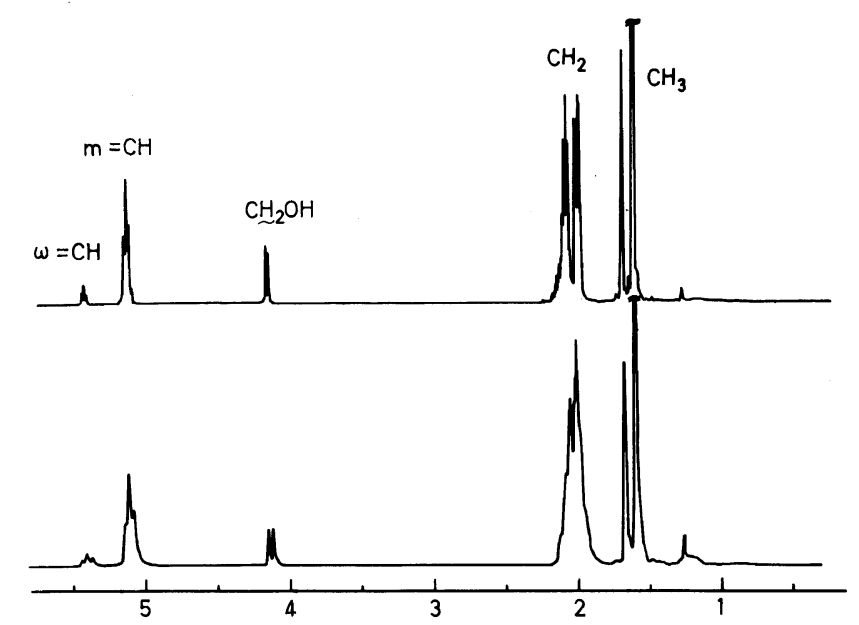

Figure 3. ${ }^{1} \mathrm{H}$ NMR spectra of soranesol measured at $50^{\circ} \mathrm{C}$ in $\mathrm{CDCl}_{3}$ at 500 (above) and $100 \mathrm{MHz}$ (below).

measurements were made five times on the same spectrometers operated at 400 and $500 \mathrm{MHz}$, respectively. The results indicate the values of $4 I S / H^{2}$ to be less than unity (Table $\mathrm{X})$. Now it is very clear that the tacticity of radically prepared PMMA slightly deviates from Bernoullian.

\section{${ }^{1}$ H NMR Spectra of Solanesol}

Solanesol is an all trans-1,4-nonaisoprene with hydroxy terminal ( $\alpha$-hydro- $\omega$-hydroxytrans-1,4-nonaisoprene). Owing to its low degree of polymerization, NMR signals of the terminal or its neighboring monomer units are distinguishable from those of in-chain units. Signal assignment was achieved by homodecoupling in ${ }^{1} \mathrm{H}$ NMR, selective decoupling in ${ }^{13} \mathrm{C}$ NMR and comparison of the spectra with those of its isomers and homologues. The results of measurements are shown in Figure 3 and Table XI.

Chemical Shift. Standard deviations of chemical shifts obtained from FT NMR instruments were smaller than those from $\mathrm{CW}$ spectrometers. Average standard deviation of chemical shift, after omitting the values for the broad signals around 2.0 and $5.1 \mathrm{ppm}$, is 0.003 with the FT method and 0.039 with the $\mathrm{CW}$ method. It is noteworthy that the mean standard deviation for the chemical shifts measured by FT method is the same order of magnitude as the digital resolution of the instruments. Relatively larger values of standard deviation for the peaks at 2.0 and 5.1 ppm may be ascribed to their broadness caused by complicated spin coupling and superimposed signals.

Intensity. Relative intensity of each signal is normalized so that the total intensity equals to 73 , which is the total number of protons, excluding the hydroxy proton, in a solanesol molecule. There is not noticeable difference between the normalized intensities obtained by the FT and CW methods. Sum of the differences between the observed $\left(I_{\text {obs }}\right)$ and the theoretical $\left(I_{\text {theo }}\right)$ intensities, $\sum\left|I_{\text {theo }}-I_{\text {obs }}\right|$, varies widely from 1 to 8 depending on the instruments used. It is not clear whether the variation results from instrumental conditions, measurement conditions, sampling method or other causes.

\section{${ }^{13}$ C NMR Spectra of Solanesol}

The ${ }^{13} \mathrm{C}$ NMR spectra were measured on 18 spectrometers $(15-125 \mathrm{MHz})$. Table XII summarizes the results of measurements. 


\section{NMR of Identical Polymer Samples}

Table XII. ${ }^{13} \mathrm{C}$ NMR chemical shifts (ppm) of solanesol measured by a number of spectrometers

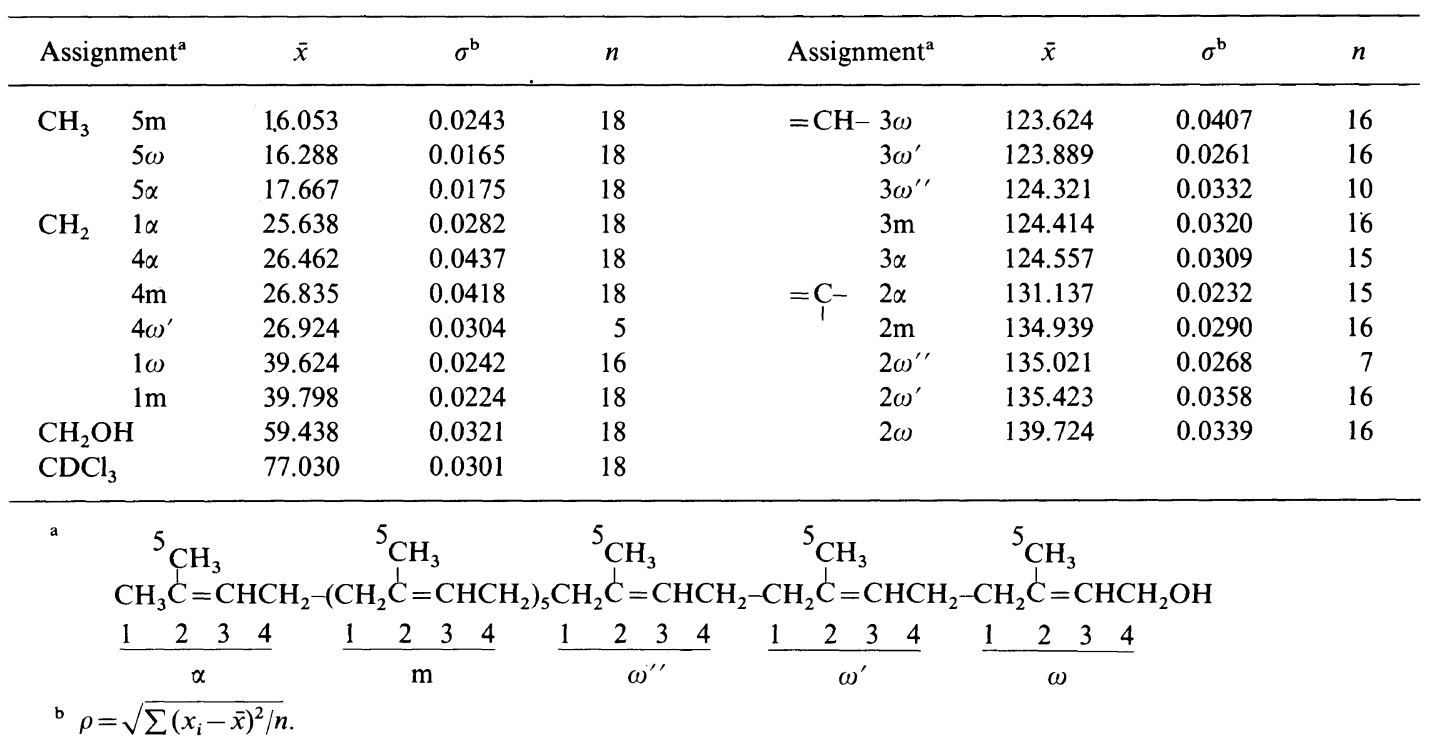

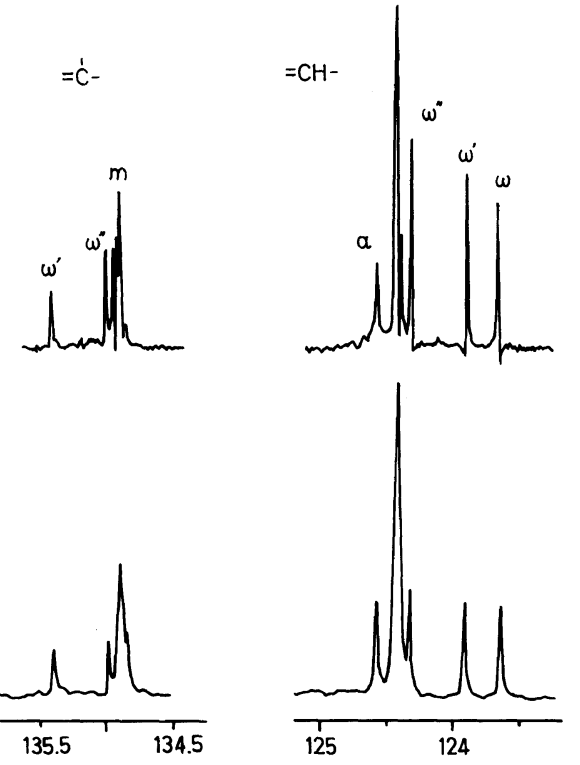

Figure 4. NMR spectra of olefinic carbons in soranesol measured at $50^{\circ} \mathrm{C}$ in $\mathrm{CDCl}_{3}$ at 125 (above) and $50 \mathrm{MHz}$ (below).

Standard deviation of each chemical shift is less than $0.05 \mathrm{ppm} .{ }^{13} \mathrm{C}$ Chemical shifts are more sensitive to the position of the monomeric unit along the molecular chain of sola- nesol than ${ }^{1} \mathrm{H}$ chemical shifts. Isoprene units along the chain are named to be differentiated as shown in Table XII. While methyl carbons in $\alpha$ - and $\omega$-units show different shifts from those in m-units, two kinds of methylene carbons in $\omega$ - and $\omega^{\prime}$-units as well as those in the $\alpha$-unit show different shifts from those in $\mathrm{m}$ units. In the case of unsaturated carbons, signals of methine and quaternary carbons in $\omega^{\prime \prime}$-unit as well as those in the $\omega^{\prime}$-unit appears separately from those of the corresponding carbons in m-units (Figure 4). Chemical shifts of these signals for $\omega^{\prime \prime}$-unit from those for munits are less than $0.1 \mathrm{ppm}$, hence these peaks can be distinguished separately only by the instruments operated at no less than $50 \mathrm{MHz}$.

\section{REFERENCES}

1. I. Ando and A. Nishioka, Kogyo Kagaku Zasshi, 73, 375 (1970).

2. K. Hatada, Y. Terawaki, H. Okuda, T. Niinomi, and H. Yuki, Kobunshi Kagaku, 28, 293 (1971).

3. B. Thiault and M. Mersseman, Org. Magn. Res., 7, 575 (1975).

4. B. Thiault and M. Mersseman, Org. Magn. Res., 8, 28 (1976).

5. R. Chûjô, H. Matsuo, and Y. Inoue, Polym. J., 6, 


\section{R. CHÛJô et al.}

569 (1977).

6. K. Hatada, Y. Terawaki, and H. Okuda, Org. Magn. Res., 9, 518 (1977).

7. C. H. Sotak, C. L. Dumoulin, and G. C. Levy, Anal. Chem., 55, 782 (1983).

8. K. Hatada, Y. Terawaki, H. Okuda, J. Ohshima, and Yuki, Kobunshi Kagaku, 29, 391 (1972).

9. R. Chûjô, K. Hatada, R. Kitamaru, F. Horii, and T. Kitayama, Polym. J., to be submitted.
10. F. A. Bovey and G. V. D. Tiers, J. Polym. Sci., 44, 173 (1960).

11. M. Reinmöller and T. G. Fox, Polym. Prepr. Am. Chem. Soc., Div. Polym. Chem., 7, 999 (1966).

12. G. Moad, D. H. Solomon, T. H. Spurling, S. R. Johns, and R. I. Willing, Aust. J. Chem., 39, 43 (1986).

13. R. Chûjô, J. Phys. Soc. Jpn., 21, 2669 (1966). 